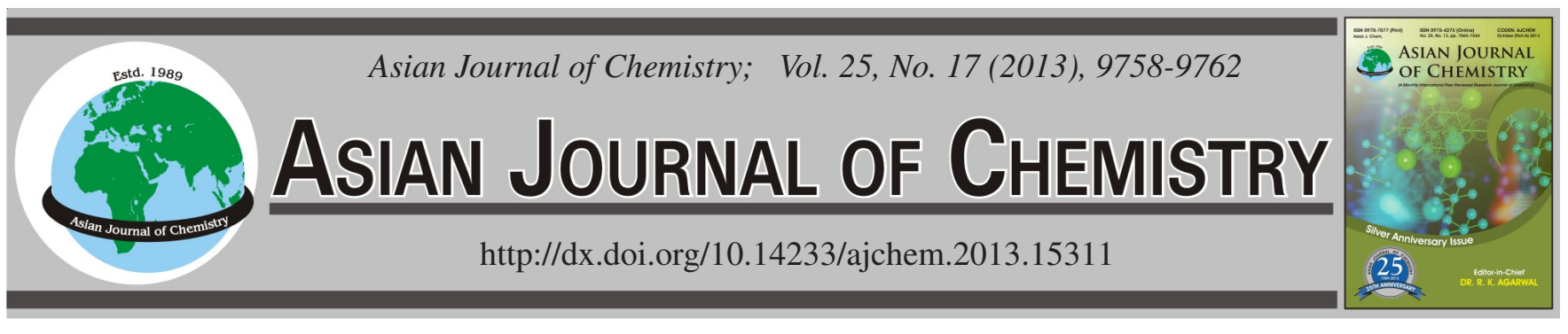

\title{
Determination of Kaempferol in Rosa canina, Urtica dioica, Terebinthina chica and Portulace oleracea by HPLC-MS
}

\author{
Cemile OzCan ${ }^{1, *}$ and Mehmet Yaman $^{2}$
}

${ }^{1}$ Department of Chemistry, Faculty of Science and Arts, Kirklareli University, Kirklareli, Turkey

${ }^{2}$ Department of Chemistry, Faculty of Sciences, Firat University, Elazig, Turkey

*Corresponding author: Fax: +90 2882179641; Tel: +90 2882461734/1150; E-mail: cemilebal23@ hotmail.com

(Received: 11 February 2013;

Accepted: 21 October 2013)

AJC-14270 The published studies on a positive association between the consumption of foods containing kaempferol and a reduced risk of developing
several disorders such as cancer and cardiovascular diseases have increased the interest in the determination of this compound in foods. A
high performance liquid chromatography-mass spectrometry (HPLC-MS) method was optimized for the determination of kaempferol in
the different four plants and fruits matrices, rose hip (Rosa canina), nettle (Urtica dioica), terebinth (Terebinthina chica) and purslane
(Portulace oleracea). Flow rate of mobile phase, fragmentor potential, injection volume and column temperature were found to be
optimum values as $0.8 \mathrm{~mL} \mathrm{~min}{ }^{-1}, 140 \mathrm{~V}, 5 \mu \mathrm{L}$ and $40^{\circ} \mathrm{C}$, respectively. Limit of quantification (LOQ) were found to be $0.2 \mathrm{mg} \mathrm{L}^{-1}$. The
optimized method was successfully applied to determination of kaempferol in the plant and fruits samples described above after their
extraction with a mixture of $\mathrm{HCl}$, methanol and ascorbic acid.

Key Words: HPLC-MS, Kaempferol, Rose hip, Nettle, Purslane, Terebinth, Flavonoids.

ᄂ - - - - - - - - - - - - - - - - - - - - - - - - - - - - - - -

\section{INTRODUCTION}

A number of plants, fruits and vegetables include kaempferol compound, but its content varies from plant to plant or even different organs such as flower, root, leaves and body of the same plant. Kaempferol is a subgroup of flavonoids that is an important group of phenolic compounds. Flavonoids are one of the most common and widely distributed groups of phenolic compounds in plants. Over 5000 different flavonoids have been described to date and they are classified into at least 10 chemical groups. Among them, flavones, flavonols, flavanols, flavanones, anthocyanins and isoflavones are particularly common in the human $\operatorname{diet}^{1-3}$. The ability of kaempferol to decrease superoxide anion, hydroxyl radical and peroxinitrite levels at submicromolar concentrations may play a key role in its antioxidant activity. As similar to other flavonoids, kaempferol has also antiinflammatory properties as well as anticancer property ${ }^{4}$. Epidemiological evidence (case-control and cohort studies) suggests that the consumption of kaempferol-rich foods may reduce the risk of developing some types of cancer, including lung cancer, gastric cancer, pancreatic cancer and ovarian cancer ${ }^{4,5}$. Further, evidence suggests that kaempferol could be used in combination with several anticancer drugs to improve their therapeutic effects ${ }^{4}$. The published studies on a positive association between the consumption of foods containing kaempferol and other flavonoids and a reduced risk of developing several disorders such as cancer and cardiovascular diseases have increased the interest in the determination of these compounds in foods ${ }^{6-8}$. These natural compounds show a powerful antioxidant activity by several ways including (1) direct trapping of reactive oxygen species (2) inhibition of enzymes responsible for superoxide anion production, (3) chelating of transition metals involved in processes forming radicals and (4) prevention of peroxidaiton process by reducing alkoxyl and peroxyl radicals ${ }^{9,10}$. Particularly, there is a necessity to thequantification of individual compounds instead of the total phenolic compounds because the methods for this purpose are not specific and detect all phenolic groups in extracts including those in the extractable proteins ${ }^{10}$. Among the flavonoids, kaempferol (3,4',5,7-tetrahydroxylflavone) has important properties due to its strong antioxidant effect which can be attributed to the high number of hydroxyl substituent groups. Kaempferol occurs mainly in its aglycones and glycosides compounds, in which one or more sugar groups such as glucose, galactose, rhamnose is bound to phenolic groups by glycosidic bonds. Glycosylation utilizes to increment in the polarity of the flavonoid molecule, which is necessary for storage in plant cell vacuoles. 
Briefly, kaempferol displays a variety of biological activities including cardiovascular protection, anticancer activity, antiulcer effects, antiallergy activity, antiviral activity and anti-inflammatory effects ${ }^{4,5,11}$. It was reported that whereas synthetic cancer drugs cause nonspecific killing of cells, natural products offer protective and therapeutic actions to all cells with low cytotoxicity and are beneficial in producing nutrient repletion to compromised people ${ }^{12}$. Thus, it is suggested that the antioxidants in natural products have more effect than the unnatural products like synthetic cancer drugs. On the other hand, flavonoids at higher doses may act as mutagens, pro-oxidants that generate free radicals and as inhibitors of key enzymes involved in hormone metabolism ${ }^{13}$. Thus, many scientists have been focused on the development of a selective, simple, low cost and accurate method for the determination of antioxidant compounds in natural products due to their important functions on health. For this purpose, chromatographic $^{14-22}$, electrochemical ${ }^{23,24}$ and spectrophotometric ${ }^{25,26}$ methods are generally used. Among them, chromatographic methods associated with mass spectrometry is superior since it provide low detection limit with a relatively free matrix effect.

Sample preparation procedure is a very important step in determination of phenolic compounds in natural samples. Solubility of these compounds is attributed to the polarity of solvent used, degree of polymerization of phenolics, as well as interaction of phenolics with other food constituents and formation of insoluble complexes. Therefore, there is no uniform or completely satisfactory procedure which is suitable for extraction of all phenolics or a specific class of phenolic substances in plant materials. Methanol, ethanol, acetone, water and ethyl acetate are frequently used for this purpose. In many studies, different concentrations of flavonoids were reported because of the different sample preparation techniques including liquid-liquid extraction, solid-phase extraction although the same chromatographic method and detection mode have been used for the determination ${ }^{10}$. Xu and coworkers found 29.2

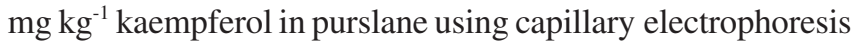
with electrochemical detection (CE-ED) after extraction with ethanol (130 mL for $10.0 \mathrm{~g}$ P. oleracea L. powder) in Soxhlet extractor for $10 \mathrm{~h}^{23}$ determined $24.32 \mathrm{mg}$ kaempferol $\mathrm{kg}^{-1}$ after extraction of the $P$. oleracea $\mathrm{L}$. powder with methanol under reflux at the boiling point of the solvent, $65^{\circ} \mathrm{C}$, for $3 \mathrm{~h}$ and using HPLC-DAD ${ }^{27}$.

In this study, the determination of kaempferol in rose hip (Rosa canina), nettle (Urtica dioica), terebinth (Terebinthina chica) and purslane (Portulace oleracea) samples was proposed. For this purpose, the mixture of dil. $\mathrm{HCl}$-methanol-ascorbic acid was used for each matrix. Then, the kaempferol concentrations in these extracts were analyzed by using HPLC-MS with positive mode electrospray ionization. Before the determination of kaempferol in these samples, the experimental conditions such as injection volume, flow rate and column temperature were optimized with standard kaempferol solution.

\section{EXPERIMENTAL}

Kaempferol hydrate was purchased from Fluka (Buchs, Switzerland). Acetonitrile, formic acid, $\mathrm{HCl}$, methanol and ascorbic acid were purchased from Merck (Darmstadt, Germany). All used solvents were of HPLC grade and other used chemicals were of analytical grade. Ultrapure water was obtained from water purification system (Millipore Direct Q). A stock solution of $500 \mathrm{mg}$ kaempferol $\mathrm{L}^{-1}$ were prepared in acetonitrile and its diluted solutions in the range of 0.2-25.0 $\mathrm{mg} \mathrm{L}^{-1}$ were freshly prepared from this stock solution and stored in refrigerator.

An Agilent 1200 HPLC-MS system was used for the quantification of kaempferol. The HPLC-MS system is consisting of an autosampler, a binary pump, a temperature controlled column oven, coupled to an Agilent 1200 MS detector operated in selected ion monitoring (SIM) and SCAN mode equipped with electrospray positive ionization. Zorbax Eclipse XDB$\mathrm{C}_{18}(4.6 \mathrm{~mm} \times 150 \mathrm{~mm}, 5 \mu \mathrm{m})$ was used a HPLC column. The analysis was performed using a solvent system including water:methanol:acetonitrile:formic acid (52:42:5:1). The flow rate, injection volume, fragmentor potential and column tempe-

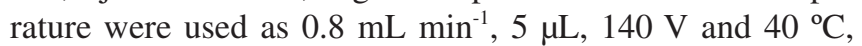
respectively, which were optimized for $8.0 \mathrm{mg}$ kaempferol $\mathrm{L}^{-1}$ (Table-1).

\begin{tabular}{cc} 
& TABLE-1 \\
\hline \multicolumn{2}{c}{ OPTIMUM CONDITIONS FOR HPLC-MS PARAMETERS } \\
\hline Mobil phase & Water:methanol:acetonitrile:formic acid \\
& $(52: 42: 5: 1)$. \\
Mobil phase flow rate & $0.8 \mathrm{~mL} \mathrm{~min}^{-1}$ \\
Column & Zorbax Eclipse XDB- $\mathrm{C}_{18}(4.6 \mathrm{~mm} \times 150$ \\
& $\mathrm{mm}, 5 \mu \mathrm{m})$ \\
Column temperature & $40^{\circ} \mathrm{C}$ \\
Fragmentor potential & $140 \mathrm{~V}$ \\
Injection volume & $5 \mu \mathrm{L}$ \\
Nebulizer (N) pressure & $60 \mathrm{psi}$ \\
Drying gas flow & $6.0 \mathrm{~L} \mathrm{~min}{ }^{-1}$ \\
Drying gas temperature & $300^{\circ} \mathrm{C}$ \\
Vaporizer temperature & $500^{\circ} \mathrm{C}$ \\
Capillary voltage & $4000 \mathrm{~V}$ \\
\hline
\end{tabular}

The HPLC effluent entered the mass spectrometer through an electrospray capillary set at $4000 \mathrm{~V}$. Nitrogen was used both as drying gas and vaporizer gas at 300 and $500{ }^{\circ} \mathrm{C}$ temperatures, respectively. Drying gas flow was adjusted to $6 \mathrm{~L} \mathrm{~min}^{-1}$ (Table-1).

Optimization of HPLC parameters: In order to optimize conditions related with HPLC-MS system, the effect of flow rate of mobile phase, injection volume, column temperature and fragmentor potential on chromatogram of kaempferol were examined. In the each studied parameter, other parameters were used as their optimum values for kaempferol solution of $10 \mathrm{mg}$ $\mathrm{L}^{-1}$ in acetonitrile. Flow rates, injection volumes and column temperatures were changed in the range of $0.4-1.0 \mathrm{~mL} \mathrm{~min}^{-1}$; 5-40 $\mu \mathrm{L}$ and $20-55^{\circ} \mathrm{C}$, respectively, for their optimization. In the MS system, the kaempferol solutions at the same concentration were studied by changing the fragmentor potential in the range of $10-200 \mathrm{~V}$ for the optimization of fragmentor potential. Other applied conditions were summarized with the obtained optimum parameters in Table-1.

Sample preparation of plant and fruit materials: Four different samples of rose hip (Rosa canina) and nettle (Urtica dioica) and three different samples of purslane (Portulace 
oleracea) were collected from the region of Elazig (Turkey) during their growing season in 2008. Further, Three different samples of terebinth (Terebinthina chica) were purchased from a seller of herbs market in Elazig. These samples were washed carefully with pure water and dried at atmospheric temperature. Then, $5 \mathrm{~g}$ of each sample was grinded at an agate mortar and the extraction steps were applied to the sample at the optimum conditions.

For the extraction of kaempferol from samples, $30 \mathrm{~mL}$ extraction solution which was consisted of the mixture of $5 \mathrm{~mL}$ of $1.2 \mathrm{M} \mathrm{HCl}, 25 \mathrm{~mL}$ of methanol and $0.9828 \mathrm{~g}$ ascorbic acid was added to $5 \mathrm{~g}$ of each dried and powdered plant. Then, the mixture was stirred at $90^{\circ} \mathrm{C}$ under reflux by Soxhlet extraction apparatus for $2 \mathrm{~h}$ to obtain aglycons by hydrolysis of the flavonol glycosides as described by Tokusoglu et al. ${ }^{28}$. The extracts were cooled to room temperature and filtered by filter paper. The each filtrate was diluted to $30 \mathrm{~mL}$ with extraction solution and then filtered through a $0.45 \mu \mathrm{m}$ filter (for terebinth a $0.20 \mu \mathrm{m}$ filter). The obtained final solutions were analyzed by HPLC-ESI-MS system using optimum conditions. The scheme of the optimized extraction procedure was given in Fig. 1.

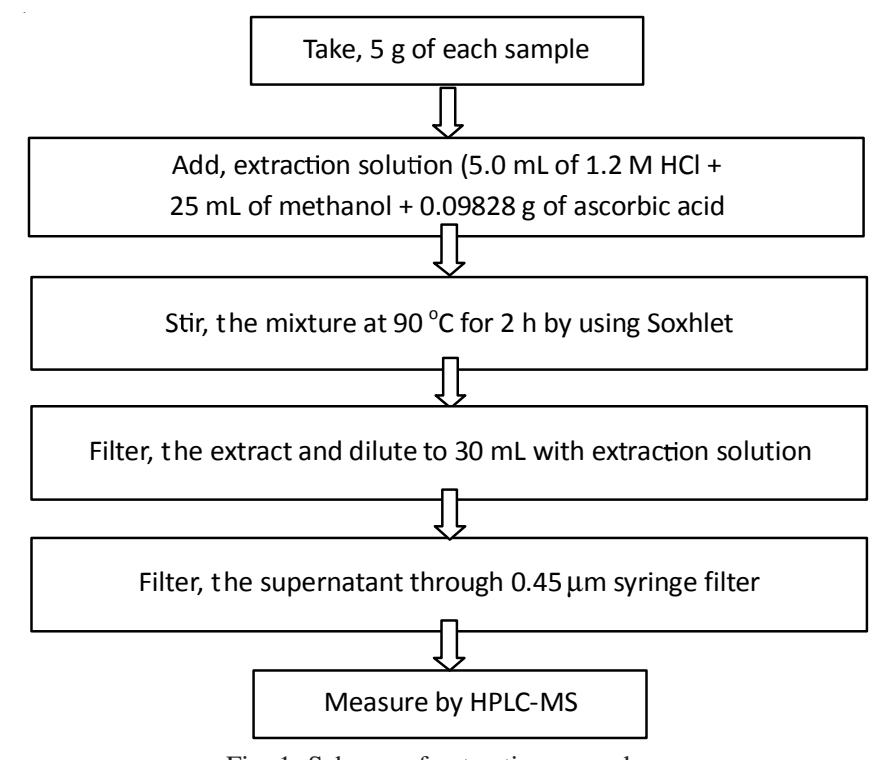

Fig. 1. Scheme of extraction procedure

Analytical study: In order to obtain linear calibration plot, different kaempferol solutions in the concentration range of $0.2-10 \mathrm{mg} \mathrm{L}^{-1}$ were prepared and analyzed at optimum conditions by using HPLC-MS method.

In order to obtain the repeatability of the method, a standard kaempferol solution of $10 \mathrm{mg} \mathrm{L}^{-1}$ was injected to column for five times. Then, the relative standard deviation (RSD) values were calculated and evaluated taking into consider the retention time and integration area. The recovery of method was investigated by standard additions method for the samples.

\section{RESULTS AND DISCUSSION}

Optimization of method: The parameters that are thought to affect the measurement steps in the analytical scheme were examined by using the kaempferol solutions of $10 \mathrm{mg} \mathrm{L}^{-1}$. In the evaluation of optimum conditions, the peak area, peak symmetry and peak height were taking into consider. Further- more, each parameter was optimized by using the other optimum conditions. In order to obtain an effective separation in chromatographic methods, firstly the best suitable column type and mobile phase should be selected. Our preliminary studies showed that the best results were obtained when we used $\mathrm{C}_{18}$ columns. Thus, Zorbax Eclipse XDB-C 18 (4.6 mm $\times$ $150 \mathrm{~mm}, 5 \mu \mathrm{m}$ ) was used a HPLC column in this study. Moreover, different mobile phases were tried and best results were obtained by using water:methanol: acetonitrile:formic acid in ratio 52:42:5:1, respectively.

In order to see the effect of flow rate on peak shape and peak area of kaempferol, the chromatograms for the solutions of $10 \mathrm{mg}$ kaempferol $\mathrm{L}^{-1}$ were recorded by using different flow rates of mobile phase. The best results were obtained when flow rate was used as $0.8 \mathrm{~mL} \mathrm{~min}^{-1}$. At the lower flow rates, the peak shape was broadening and retention time was found to be very high. Thus, when the peak shape, retention time and also peak area were taking into consider, the flow rate of $0.8 \mathrm{~mL} \mathrm{~min}^{-1}$ was found as an optimum value.

To obtain optimum fragmentor potential, the chromatograms of $10 \mathrm{mg} \mathrm{L}^{-1}$ were recorded by using different fregmentor potantials in the range of 10-200 V. From the results obtained, the maximum peak areas were found between 120 and $180 \mathrm{~V}$. Due to obtaining maximum value in peak height at $140 \mathrm{~V}$, this fragmentor potential was chosen as optimum value.

In order to obtain the optimum injection volume, the chromatograms obtained by using different injection volumes were recorded for the kaempferol solutions at the same concentration. These chromatograms indicated that the best result was obtained for $5 \mu \mathrm{L}$ of injection volume. Furthermore, the peak symmetry was changed when the injection volume was higher than $5 \mu \mathrm{L}$. Thus, $5 \mu \mathrm{L}$ was chosen as the optimum injection volume. Finally, the column temperature was optimized. For this purpose, the separately kaempferol solutions at the same concentration were examined by using different column temperatures between 20 and $55^{\circ} \mathrm{C}$. From the obtained peak areas, the temperature of $40^{\circ} \mathrm{C}$ was chosen as optimum and this temperature was used for subsequent studies. The obtained optimum conditions and HPLC-MS parameters were summarized in Table-1.

Analytical performance: The validation of this method for kaempferol was performed by investigation of different parameters like linearity, sensitivity, precision and accuracy. The obtained chromatograms for some standard kaempferol solutions were given in Fig. 2. Fig. 2 shows linearity at the concentration range of $0.2-4.0 \mathrm{mg} \mathrm{L}^{-1}$.

The sensitivity of the method was determined with respect to LOQ and this value was found to be $0.2 \mathrm{mg} \mathrm{L}^{-1}$. This result indicates that the sensitivity of proposed method is good for determination of kaempferol in the studied samples taking into consider the concentration. Related with the precision, relative standard deviation (RSD) was found to be $7 \%$.

Validation of the method was checked by determination of the recoveries during standard additions method. The selected ion monitoring chromatograms related with the standard additions method for rose hip were given in Fig. 3. The observed peak around $4 \mathrm{~min}$ in this Figure are attributed to other polyphenols except for kaempferol. The recoveries 


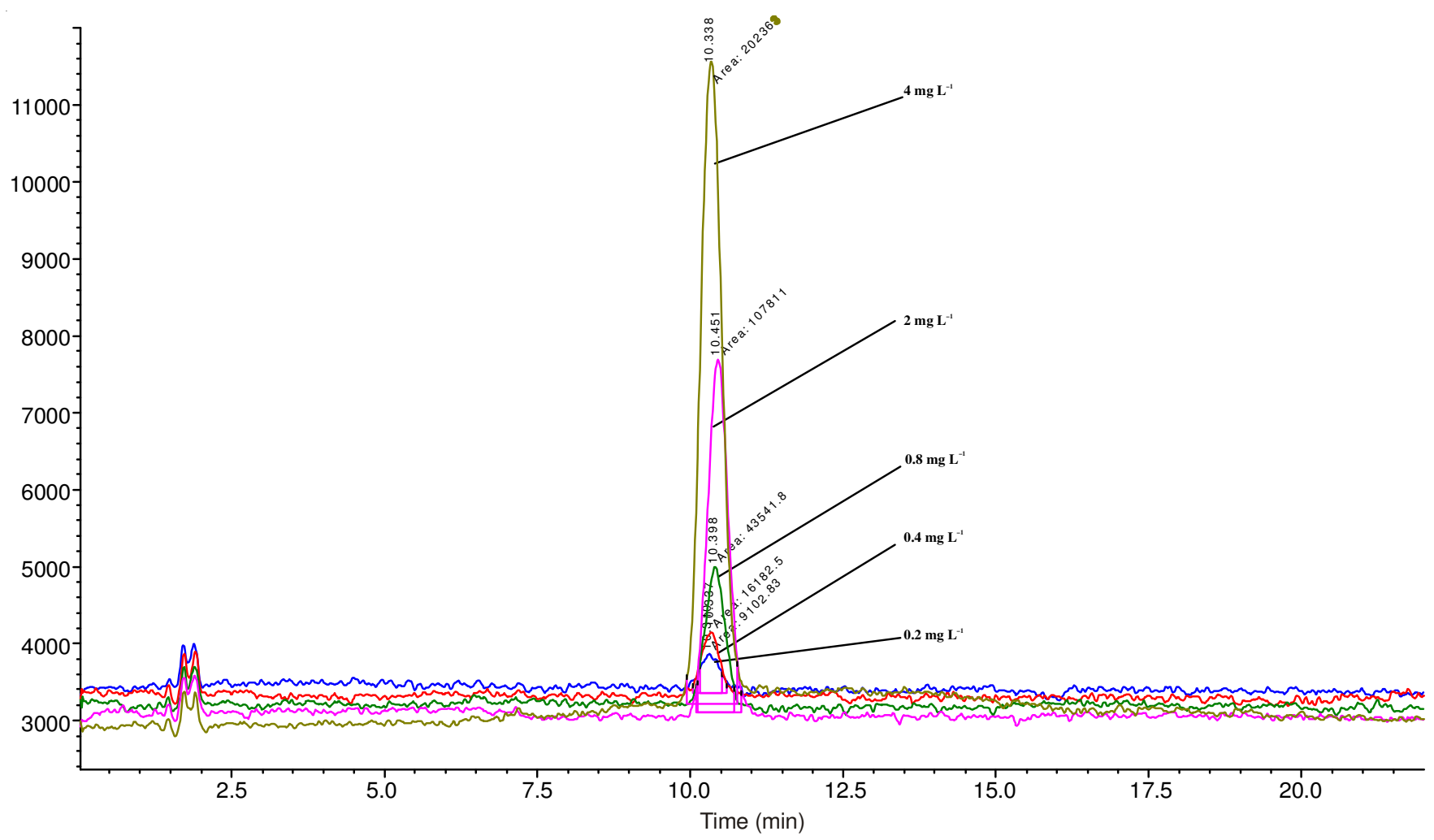

Fig. 2. Chromatograms of kaempferol with different concentrations. Inset shows the plot of peak area $v s$. the concentration of kaempferol

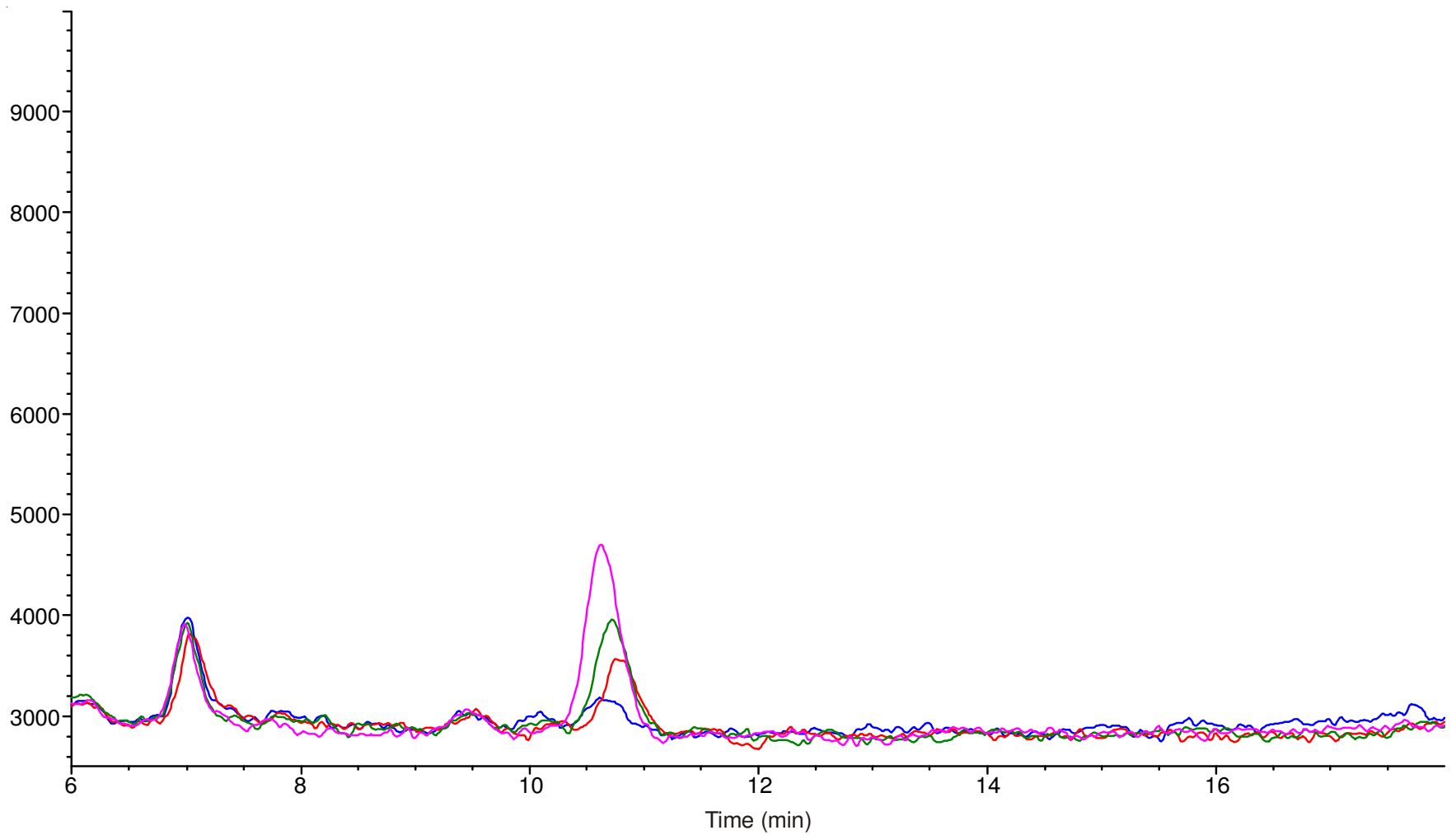

Fig. 3. HPLC-MS chromatograms obtained from standard addition method for rose hip extraction: (a) rose hip extract (b) a $+0.2 \mathrm{mg} \mathrm{L}^{-1}(\mathrm{c}) \mathrm{a}+0.4 \mathrm{mg} \mathrm{L} \mathrm{L}^{-1}$ (d) $\mathrm{a}+0.8 \mathrm{mg} \mathrm{L}^{-1}$. Inset shows calibration curve for standard solution of kaempferol and standard addition method

for kaempferol were found to be, at least, $90 \%$. Furthermore, the slope of calibration curve was compared with the slope obtained by the standard additions method (Fig. 3). The slopes of both calibration curves were found very similar to each other. Because the slopes of calibration curve and standard additions method are identical, it was concluded that the calibration curve could be used for the quantitative analysis. Thus, we can say that, there isn't any meaningful interference effect on the determination of kaempferol in rose hip. These results showed that the optimized method was reliable for the analysis of kaempferol. 
Applications: It is well known that, kaempferol is generally found as its glycosidic form in plants. However, free flavonol aglycones can be produced from their glycosides via hydrolysis of the glycosidic bond by enzymes or acidic conditions. In order to indentification of the kaempferol in aglycone form, HPLC-MS analysis were performed in positive mode. In the selected ion monitoring (SIM) chromotograms, a main peak was observed at precursor ion $\mathrm{m} / \mathrm{z} 287$. This peak was attributed to the characteristic peak of kaempferol in aglycone form. Yang and coworkers also reported that a peak at $\mathrm{m} / \mathrm{z}, 287$ obtained from MS spectrum of lotus petals in positive ion mode demonstrated the identification of kaempferol ${ }^{15}$.

The concentrations obtained for kaempferol in the studied samples were summarized in the Table-2. Table- 2 shows that the contents of kaempferol varied from 4.2-6.1 (average 5.2) $\mathrm{mg} \mathrm{kg}^{-1}$ for Rose hip, 16-24 (average 20) $\mathrm{mg} \mathrm{kg}^{-1}$ for Nettle, 3.7-5.4 (average 4.6) $\mathrm{mg} \mathrm{kg}^{-1}$ for purslane and $<$ d.1-2.2 mg $\mathrm{kg}^{-1}$ for terebinth on the basis of dry weight.

\begin{tabular}{cc} 
TABLE-2 \\
OBTAINED RESULTS FOR DETERMINATION \\
OF KAEMPFEROL IN THE STUDIED SAMPLES $(\mathrm{n}=3)$ \\
\hline Sample & Concentration of KF $\left(\mathrm{mg} \mathrm{kg}^{-1}\right)$ \\
\hline Purslane 1 & $4.8 \pm 0.6$ \\
Purslane 2 & $3.7 \pm 0.5$ \\
Purslane 3 & $5.4 \pm 0.7$ \\
Purslane average & $4.6 \pm 0.9$ \\
Nettle 1 & $16 \pm 2$ \\
Nettle 2 & $24 \pm 3$ \\
Nettle 3 & $19 \pm 2$ \\
Nettle 4 & $21 \pm 3$ \\
Nettle average & $20 \pm 3$ \\
Rose hip 1 & $5.3 \pm 6.8$ \\
Rose hip 2 & $4.2 \pm 4.1$ \\
Rose hip 3 & $6.1 \pm 7.2$ \\
Rose hip average & $5.2 \pm 1.0$ \\
Terebinth 1 & $<\mathrm{d} .1$ \\
Terebinth 2 & $<\mathrm{d} .1$ \\
Terebinth 3 & $2.2 \pm 0.4$ \\
\hline
\end{tabular}

When kaempferol results obtained from this method were compared with those obtained from literature, the kaempferol levels were found in the range of reported values. For example, Huang and coworkers analyzed the phenolic composition of vegetables commonly consumed by African-Americans in the southeast United States with HPLC-MS ${ }^{16}$. They found the kaempferol concentrations in collard greens, mustard greens, kale, okra, sweet potato greens, purple hull peas and purslane in the range of 11-905 mg kg-1, on fresh basis. The highest and lowest kaempferol content was found in kale (905 $\mathrm{mg} \mathrm{kg}^{-1}$ ) and purslane $\left(11 \mathrm{mg} \mathrm{kg}^{-1}\right)$, respectively, in their study ${ }^{21}$. However, in our study the highest kaempferol level was found in rose hip (24 mg kg-1) while the lowest level was found in Terebinth (< d.1.). In another study, kaempferol content of Urtica sp., Rosa canina (rosehip), Salvia officinalis (sage), Tilia platyphyllos (linden flower), black tea, Daucus carota L. spp sativus (violet carrot juice), grape molasses, honey and tarhana were determined by HPLC with UV detection ${ }^{29}$. The kaempferol contents of liquid samples including black tea and linden flower were found to be 110 and $113 \mathrm{mg} \mathrm{L}^{-1}$, respectively, while kaempferol in other matrices were below the LOQ.

\section{Conclusion}

The presented study describes a simple and optimized HPLC-MS analytical method for the determination of kaempferol in four different plant samples. The method was validated in terms of linearity, precision, accuracy and sensitivity using the optimum parameters. The change in kaempferol concentration is in descending order nettle, purslane, rose hip and terebinth.

\section{REFERENCES}

1. M. Jahangir, H.K. Kim, Y.H. Choi and R. Verpoorte, Comp. Rev. Food Sci. Food Safety, 8, 31 (2009).

2. G. Dinelli, A. Bonetti, M. Minelli, I. Marotti, P. Catizone and A. Mazzanti, Food Chem., 99, 105 (2006).

3. U. Justesen and P. Knuthsen, Food Chem., 73, 245 (2001).

4. J.M. Calderón-Montaño, E. Burgos-Morón, C. Pérez-Guerrero and M. López-Lázaro, Mini-Rev. Med. Chem., 11, 298 (2011).

5. J. Lameira, C.N. Alves, V. Moliner and E.A. Silla, Eur. J. Med. Chem., 41, 616 (2006).

6. H.C. Hung, K.J. Joshipura, R. Jiang, F.B. Hu, D. Hunter, S.A. SmithWarner, G.A. Colditz, B. Rosner, D. Spiegelman and W.C. Willett, J. Nat. Cancer Inst., 96, 1577 (2004).

7. B. Halliwell, Lancet, 344, 721 (1994).

8. M.G.L. Hertog, E.J.M. Feskens, P.C.H. Hollmann, M.B. Katan and D. Kronthout, Lancet, 342, 1007 (1993).

9. G. Williamson and A. Carughi, Nutr. Res., 30, 511 (2010).

10. M. Naczk and F. Shahidi, J. Chromatogr. A, 1054, 95 (2004).

11. I.S.L. Lee, M.C. Boyce and M.C. Breadmore, Food Chem., 133, 205 (2012).

12. L. Reddy, B. Odhav and K.D. Bhoola, Pharmacol. Therap., 99, 1 (2003).

13. C.F. Skibola and M. Smith, Free Radic. Biol. Med., 29, 375 (2000).

14. E. Aguirre-Hernández, M.E. González-Trujano, A.L. Martínez, J. Moreno, G. Kite, T. Terrazas and M. Soto-Hernández, J. Ethnopharmacol., 127, 91 (2010).

15. R.Z. Yang, X.L. Wei, F.F. Gao, L.S. Wang, H.J. Zhang, Y.J. Xu, C.H. Li, Y.X. Ge, J.J. Zhang and J. Zhang, J. Chromatogr. A, 1216, 106 (2009).

16. Z. Huang, B. Wang, D.H. Eaves, J.M. Shikany and R.D. Pace, Food Chem., 103, 1395 (2007).

17. M. Vagiri, A. Ekholm, S.C. Andersson, E. Johansson and K. Rumpunen, J. Agric. Food Chem., 60, 10501 (2012).

18. W. Zheng and S.Y. Wang, J. Agric. Food Chem., 49, 5165 (2001).

19. B. Sultana and F. Anwar, Food Chem., 108, 879 (2008).

20. K.H. Park, P. Garm de Oca, G.A. Bonello, K.J. Lee and K. Dabrowski, Aquacult. Int., 17, 537 (2009).

21. Q. Zhang and H. Cui, J. Sep. Sci., 28, 1171 (2005).

22. Y. Sun, T. Guo, Y. Sui and F. Li, J. Sep. Sci., 26, 1203 (2003).

23. X. Xu, L. Yu and G. Chen, J. Pharm. Biomed. Anal., 41, 493 (2006).

24. P. Xiao, F. Zhao and B. Zeng, Microchem. J., 85, 244 (2007).

25. B. Harbaum, E.M. Hubbermann, Z. Zhu and K. Schwarz, J. Agric. Food Chem., 56, 148 (2008).

26. I. Baranowska and D. Rarog, Talanta, 55, 209 (2001).

27. N. Erkan, Food Chem., 133, 775 (2012).

28. O. Tokusoglu, M.K. Unal and Z. Yildirim, Acta Chromatogr., 13, 196 (2003).

29. S. Karakaya and S. El-Nehir, Food Chem., 66, 289 (1999). 